\title{
Measuring and Improving Employee Engagement (A Study in PT. Svara Inovasi Indonesia)
}

\author{
Adam Kurnia Oktanofa, Fredo Adrian Arliawan, and Aurik Gustomo \\ School of Business and Management, Institut Teknologi Bandung, Indonesia \\ e-mail:adam_kurnia@sbm-itb.ac.id
}

\begin{abstract}
For the past 15 years, radio and music industry trend is decreasing. One of the causes is "disruption" from Radio Internet Pureplay such as Spotify, Joox, etc. Svara came with "Beyond Disruption" concept that can be saved radio and music industry by starting Radio Digital Transformation. Nowadays, the growth of IT Start-Up Company keeps increasing. which also followed by the increased number of skilled IT workers. The turnover rate over the IT Company also increases. Most of the employees stayed for a short period then moved to another company. This high turnover rate causes decrease in productivity that affected the revenue of the company since low level of employee engagement. In this paper, PT Svara Inovasi Indonesia will be studied and improved employee engagement. The factors of employee engagement level are measured through the data collected by questionnaire. The main objective of the study was to measuring and improving the employee engagement level on PT Svara Innovasi Indonesia. To measure employee engagement with suggestive improvements, the study uses 3 models; Gallup Q12, Aon-Hewitt Employee Engagement Driver, and Deloitte Simply Irresistible Organization model. The result is identified that "stay" component from employee engagement level is low. This caused by low level of recognition, rewards, and work-life balance. This could be improved to increase engagement level, productivity and reducing turnover.
\end{abstract}

Keywords-Aon-Hewitt, Deloitte, Employee Engagement, Gallup Q12, Start-Up Company.

\section{INTRODUCTION}

$\mathrm{T}$ HE growth of technology in Indonesia nowadays is increasing exponentially. A lot of startup in the technology or IT sector keep growing. The amount of new start-up company is directly proportional with the need of IT talent or skilled IT people with great quality in Indonesia. This lack of skilled IT Company can inhibit the growth of IT company. Besides, the new comers of IT Start-up Company tend to recruit fresh graduates who has no work experience. The graduates are easy to mold (Isabel Brehcist, Why hire graduates at your start-up?, 2018). Since the growth of IT start-up is started around 1990s until 2000s, the Company employees are mostly come from fresh graduate worker which is considered as millennial worker. Millennial workers tend to have the "job-hopping" behavior. They choose the job they wanted, and if they don't feel comfortable with the company, they hop into more comfortable company. As the startup company still grow their business, this job-hopping behavior can bring the most significant impact on productivity (Alcacer and Zhao, 2008).

With vast Startup sector that grow in Indonesia The founder of Svara took the opportunity in creative industry sector, which is music and radio industry.

\section{A. Company Profile}

The basic idea starts with the business of the radio and music industry in the past 15 years decreased. One of the reason of declining rate is a technology disruption that have been done by internet based radio such as Spotify, Joox, TuneIn, SoundCloud, dll. Svara comes with the concept of "Beyond Distruption" by saving the conventional radio and music industry without disrupting existing industries by starting with Transforming Radio to Digital Platform.

PT Svara Inovasi Indonesia Is a Start-Up that focus on providing audio digital platform services. The development of Svara technology started since 2002. PT Svara Innovasi Indonesia has 2 business sector such as business to customer that providing podcast called Svara that can be downloaded in playstore. Over 80 private radio has joined as Early Adopter and has advertising spots approximately twenty five thousand commercial per month. The radio stations ready to begin the Radio Digital Transformation by using Svara Platform. PT Svara has their own product in form of an application for user. There are Svara Online and Svara On-Air. For Svara Online, this product app is for mobile phone user, to easy listening radio everywhere digitally. While the Svara On-Air is for the announcer or for the radio stations. PT Svara Inovasi Indonesia located in Gd. SALMAN-ITB, Lantai 2, Jl. Gelap Nyawang No.4, Bandung, Jawa Barat, 40132. The total of the employee is 20 with additional 10 internship..

B. Business Issue

For over 2 years, Svara develop and improved each year, and aiming for company sustainability. They recruit their employee with attitude first and skill can be learned. Preliminary interview with two employee was held at 28th September around 2 PM.

"As a small team, we have a lot of work to do. Each of developer can held 2 until 3 projects at the same time. With this workload, I feel that I have less time for myself. So every day for more than office hour is work, work, and work. I don't feel that I've been paid enough for this workload. I join here to add my

work experience, and I think I planned to stay here maybe 4 to 6 months" Said by employee A.

"Our work hour time is flexible. We even stayed late in the office in order to finish the projects. We do get paid more when we worked overtime, but still it's not much as I expected" Said by employee B.

Based on the employee statement in Svara, they have high workload, less likely to stay longer, and less life balance. The work-life balance still not implemented since the developer team must stay on schedule. Many of them stay over the night in the office. They feel the benefits and pay still not enough 
The $1^{\text {st }}$ International Conference on Business and Engineering Management (IConBEM)

February $1^{\text {st }} 2020$, Institut Teknologi Sepuluh Nopember, Surabaya, Indonesia

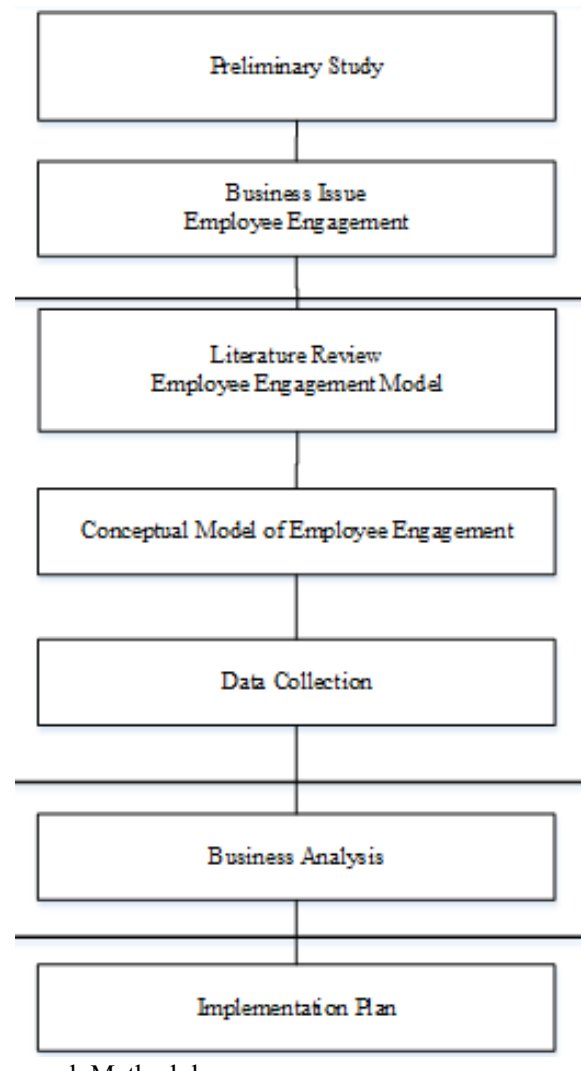

Figure 1. Research Methodology.

for them regarding to the workload. Employee turnover rate ratio is almost 1:1. By two years Svara operates, the employee turnover data is shown in Table 1

The research objective for Svara are to identify driver variable that dominately affected to the employee engagement which has the most weak point and giving big impact, and improving the employee engagement and reduced employee retention.

The research questions are "What is the most weak driver factor that affected the employee engagement?"

"How to improve employee engagement in order to reduce employee retention?"

Based on business issue, the main problem in PT Svara is employee engagement. Their employee lacks of satisfaction because of high workload and unclear compensation and incentives. Work life balance still needed to be reconstructed and more elaborated. In order to fulfill research goals, conceptual framework need to be defined to understand more which employee engagement model to be applied. The framework of employee engagement in this research based on Gallup, Aon Hewitt, and Deloitte models.

This research is focused in in PT Svara Inovasi Indonesia to solving the problem to minimize employee turnover.

\section{METHOD}

Research Methodology contain several levels that map the steps required from previous knowledge and observation of subject research. Every level connected to each other and explained in every chapter. This research is to find the solution from business issue, which is employee engagement and job satisfaction affected the company performance. Figure 1 below shown the research method.

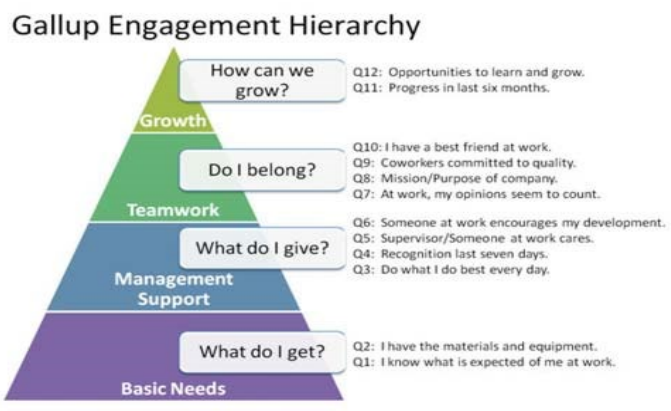

Figure 2. Gallup Hierarchy and Q12.

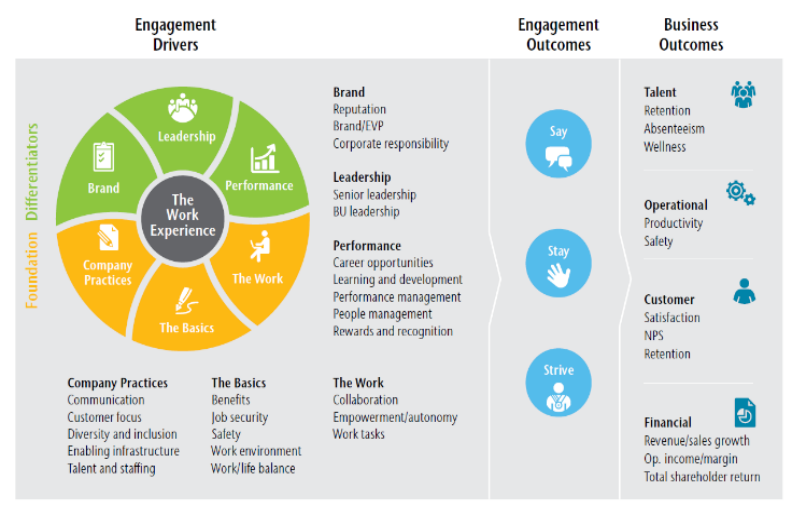

Figure 3. Aon Hewitt Engagement Model

The methods of this research is started with preliminary study that can resulted the business issue of employee engagement. In the next chapter, will be included the literature review of employee engagement model. The three model will be combined and synthesized into conceptual odel of employee engagement. After the conceptual model has been created, Data collection will be held by using quantitative method such as spreading the questionnaire. From the result of data conclusion, will be analyzed in order to match with the business issue. After analyzing the lowest factor, the implementation plan should be applied as the proposed solution to increase the business issue which is the low level of employee engagement.

According to Gallup, there are 3 types of employee responded to employee engagement and divided based on Gallup 12 questions model, such as Engaged, Not Engaged, and Actively Disengaged (Gallup 2017). According to Aon Hewitt (2018), there're 5 factors that drive employee engagement such as agility, engaged leader, talent focus, the work, and the basics (AON Hewitt, 2018). According to Deloitte (2015), the organization must be irresistible based on five major element drive engagement, such as meaningful work, hands-on management, positive work environment, growth opportunity, and trust in leadership.

\section{Employee Engagement}

Employee Engagement is a measureable degree of an employee's positive or negative emotional attachment to their job, colleagues and organization which profoundly influences their willingness to learn \& perform at work. (Source: Scarlett Surveys)

An engaged employee is one who is fully involved in, and enthusiastic about, his or her work and thus will act in a way that furthers their organization's interests. Engagement is seen 


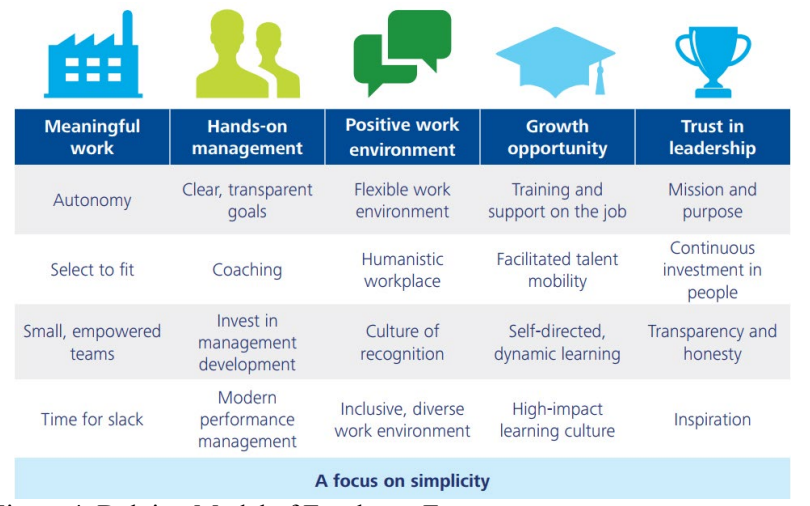

Figure 4. Deloitte Model of Employee Engagement.

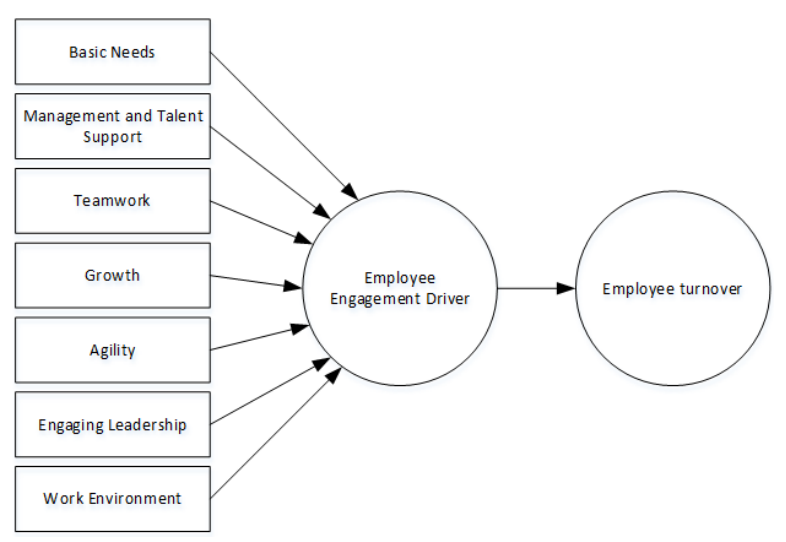

Figure 5 Conceptual Model Framwork of Employee Engagement.

as a positive attitude to the job and it is distinguished from both job satisfaction and commitment. It is more temporary and volatile than commitment, which is a more stable perception.

Employee Engagement is the means or strategy by which an organization seeks to build a partnership between the organization and its employees, such that employees fully understands and committed to achieve the organization's objectives, and the organization respects the personal aspirations and ambitions of its employees.

A definition of a fully engaged employee is intellectually and emotionally bound with the organization, always gives maximum effort, feels passionately about its goals, committed to live by its values, proud to work there, and recommend their workplace to others. The employee could goes beyond the basic job responsibility to delight the customers and drive the business forward and increasing business revenue.

\section{Conceptual Framework of Employee Engagement Model}

To develop the conceptual framework of Employee Engagement, three models has been used such as Gallup, Aon-Hewitt, and Deloitte.

\section{1) Gallup Employee Engagement Model}

Gallup's employee engagement work is based on more than 30 years of in-depth behavioral economic research involving more than 17 million employees. Through rigorous research, Gallup has identified 12 core elements which called "The Q12" that link powerfully to key business outcomes. Gallup's Q12 employee engagement measurement tool is designed to initiate companywide transformation to create sustainable growth. This tool is backed by rigorous science linking it to nine integral performance outcomes. These 12 statements
Table 1.

Employee Turnover ratio

\begin{tabular}{llll}
\hline \hline Year & Quarter & Applied & Resign \\
\hline 2018 & $1^{\text {st }}$ & 3 & 2 \\
& $2^{\text {nd }}$ & 4 & 3 \\
& $3^{\text {rd }}$ & 5 & 3 \\
& $4^{\text {th }}$ & 2 & 2 \\
& $1^{\text {st }}$ & 4 & 3 \\
& $2^{\text {nd }}$ & 5 & 3 \\
& $3^{\text {rd }}$ & 2 & 2 \\
& $4^{\text {th }}$ & 2 & 2 \\
\hline \hline
\end{tabular}

Table 2.

Demography around Surabaya.

\begin{tabular}{llll}
\hline \hline Demography & & Total & $\%$ \\
\hline Gender & Male & 13 & $59,1 \%$ \\
& Female & 9 & $40,9 \%$ \\
Generation & Baby & 1 & $4,5 \%$ \\
& Boomers(>1964) & & \\
& Gen X (1965-1976) & 1 & $4,5 \%$ \\
& Gen Y/ millennials & 9 & $40,9 \%$ \\
& (1977 - 1995) & & \\
& Gen Z (1996- & 11 & $50,0 \%$ \\
Work & Present) & & \\
Experience & Under 1 Year & 15 & $68,2 \%$ \\
(Years) & 1,5 years & 3 & $13,6 \%$ \\
\hline \hline
\end{tabular}

emerged as those that best predict employee and workgroup performance. The Twelve Questions are shown in Figure 2.

\section{2) Aon Hewitt Model Of Employee Engagement}

The Aon Hewitt engagement model above includes the organizational drivers and business outcomes of engagement as well as the individual engagement outcome itself. Aon defines engagement as the psychological state and behavioral outcomes that lead to better performance. Engagement is thought to include a combination of several constructs widely accepted in academic literature such as affective and continuance commitment, motivation, and organizational citizenship behaviors. Practically speaking, this means engagement involves a combination of rational thought, emotions, intentions, and behaviors required for optimal performance and productivity. More importantly, Aon's scientifically-proven methodology provides a solution for improving employee performance and well-being that directly correlates to positive and tangible business outcomes. Focusing on engagement outcomes improves employee performance such as "say, stay, and strive"

-Say - Employees speak positively about the organization to coworkers, potential employees, and customers

-Stay - Employees have an intense sense of belonging and desire to be part of the organization

-Strive - Employees re motivated and exert effort toward success in their job and for the company

The Engagement driver of Aon-Hewitt is shown in Figure 3.

\section{3) Deloitte Employee Engagement Framework}

Deloitte uncovered five major elements (and 20 underlying strategies) that work together to make organizations "irresistible." These 20 factors fit together into a whole system of engagement in an organization that shown in Figure 4. These 20 factor is classified into 5 major factor such as:

\section{a. Make work meaningful}

The first and perhaps most important part of employee engagement is job person fit. We need to make sure jobs are 
The $1^{\text {st }}$ International Conference on Business and Engineering Management (IConBEM)

February $1^{\text {st }} 2020$, Institut Teknologi Sepuluh Nopember, Surabaya, Indonesia

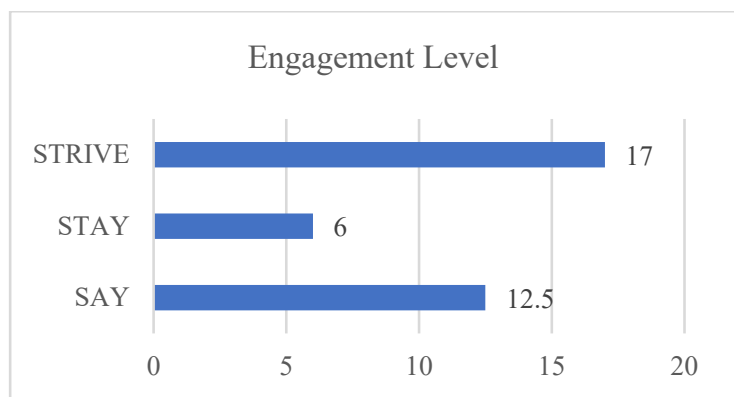

Figure 6. Enganement level.



Figure 7. Basic Needs.



Figure 8. Work Driver

meaningful, people have the tools and autonomy to succeed, and that we select the right people for the right job. This is anything but a simple undertaking.

It may seem counterproductive to let people take time off during the week, but in fact the opposite is true. Overworked people tend to burn out, produce lower quality output, provide lower levels of customer service, become depressed, and sometimes just flail around in their exhaustion.

\section{b. Great Management}

It is important for companies to remember that management's job is not to manage work but rather to develop, coach, and help people. Rewarding managers only for making their numbers incentivizes what we call "talent hoarding:" attracting the best people and holding onto them for years. To help people get the coaching and support they need to grow, forward-thinking companies reward managers for what we call "talent production:" developing people who leave their teams. This culture of continuous development is a management culture widely used in high engagement companies.

\section{c. Positive work enfironment.}

The third major element of an irresistible organization is the need to build a flexible, humane, and inclusive workplace. The first key if leaders want people to engage with their



Figure 9. Teamwork

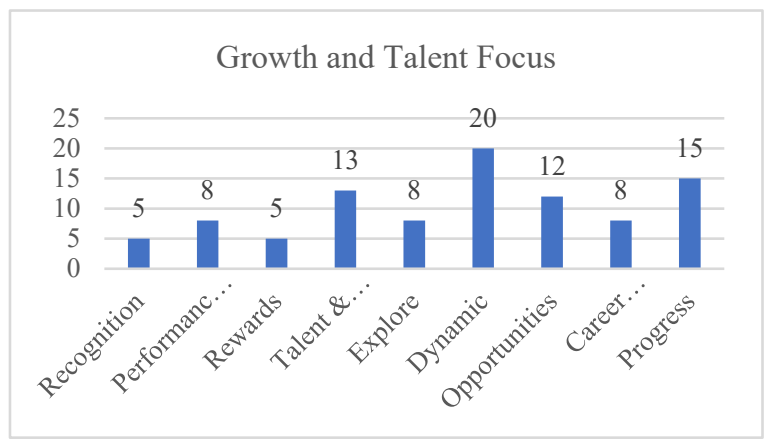

Figure 10. Growth and Talent Focus

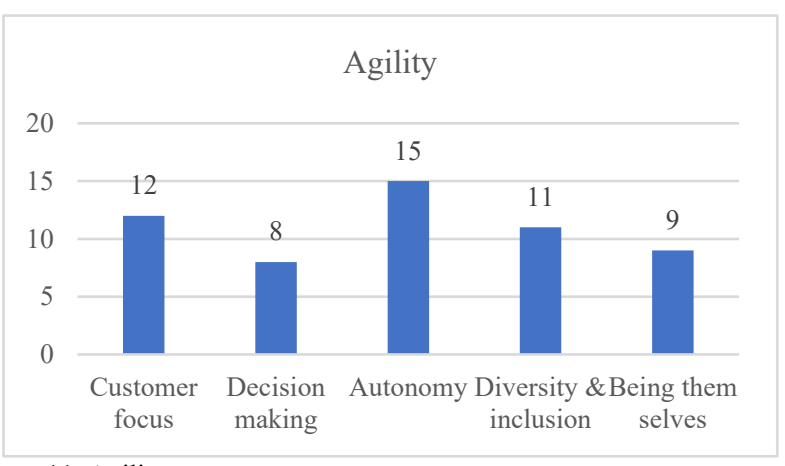

Figure 11. Agility.

organizations, they have to give them a flexible and supportive work environment.

A second key engagement driver is the need for continuous and ongoing recognition. High-recognition companies" have 31 percent lower voluntary turnover than companies with poor recognition cultures. Companies should build a culture of recognition through social reward systems (tools that give people points or kudos to reward to others), weekly or monthly thank-you activities, and a general culture of appreciating everyone from top to bottom. The key to success here is to create a social environment where recognition can flow from peer to peer, freeing managers from being the judge and jury of employee recognition

\section{d. Growth Opportunities}

Building opportunities for growth is a complex and systemic challenge. First, there must be developmental opportunities, both formal and informal, that let people learn on the job, take developmental assignments, and find support when they need help. This means designing onboarding and transition management programs, developing a culture of support and learning, and giving people time to learn.

Second, a company must support and honor what we call facilitated talent mobility. Most people will not be promoted every year or two, but they want to feel that they are growing and can take on new assignments in their chosen area. 
The $1^{\text {st }}$ International Conference on Business and Engineering Management (IConBEM)

February $1^{\text {st }} 2020$, Institut Teknologi Sepuluh Nopember, Surabaya, Indonesia

Managers and the company as a whole need to support and facilitate internal mobility, giving people the freedom to try something new and move from a role where they are highly productive to one where they may be a trainee again.

Finally, organizations must look at their management and leadership behaviors to make sure that learning, development, and mobility are rewarded. While this is certainly important, leaders must also be rewarded for developing people, moving people into the best role, and keeping retention high.

\section{e. Trust in Leadership}

The final and perhaps most important element in the irresistible organization is leadership. Our research suggests that four leadership practices most directly impact employee engagement. The first is to develop and communicate a strong sense of purpose. When organizations define their success through the eyes of their customers, stakeholders, or society, people come alive.

The second important element in leadership today is transparency. New research shows that among Millennials, transparency from leadership rates as among the most important drivers of company loyalty. Third, leaders must continuously invest in people. High-engagement companies have executives who spend money in learning, regularly meet with teams and provide feedback, and genuinely care about each individual.

Finally, In figure 5 senior leaders must continuously focus on inspiration. Through their words, communications, and actions, it is the top executives

who ultimately engage everyone in the organization. By talking about the future, sharing the vision, and translating the business strategy into meaningful, personal concepts, leadership can be one of the most important drivers of engagement.

\section{f. Synthesis Model}

The driver for employee engagement will be synthetize into conceptual model of employee engagement according to three different framework model. Between the three models, there are some driver that overlap. For example, the three models have same driver in growth opportunity and talent support. But some of the driver only exist on one model. This can be combined to create new model as the synthesixe result.

This research will be doing with one types of methods, quantitative. The quantitative will collected by quesitionnaire based on the framework model in this research. Sample taken was population of PT Svara $100 \%$.

\section{RESULTS AND DISCUSSION}

The result and data analysis research will be provided and used to answer the research problem. This data analysis is using statistical descriptive based on data that obtained from research quistionnaire. The quistionnaire result will be shown in table and chart form, where the measurement is charted based on likert chart 6 level. SS means "Sangat Setuju" or Fully agree. S means "Setuju" or Agree. AS is "Agak Setuju" or likely to agree. ATS is "Agak Tidak Setuju" or likely to disagree. TS is "Tidak Setuju" or disagree, and STS means "Sangat Tidak Setuju" or not agree at all.
The engagement survey was designed to measure the level of employee engagement in Table 2, and to capture the factor that affect the employee. The quistionnaire that has been spread was targeted to all employees in PT Svara Inovasi Indonesia. From total 22 employees has been asked, all of them responded, meaning $100 \%$ responded. This table below shown the demography of respondent such as gender, ages and their years of working.Majority of respondent are male, and dominated with millennial age, and having a working time experience under one year.

Based on preliminary interview and the questionnaire result, it is proven that the less likely to stay for a long period of time. Since the demography at Svara is dominated by millenials, and they most likely a generation to switch jobs (Gallup, 2017). To identify the factor that drive this stay level low, the employee engagement driver should be analyzed from the questionnaire result in the sub chapter below.

\section{E. Employee Engagement Driver Result}

There are categories of engagement driver that split up to question on each driver in Figure 6. The driver is the result of joining three models of engagement.

\section{1) Basic Needs}

The basic needs for employee driver in Figure 7. It consist of job security, trust, work environment, safety, expected, and equipment. As the basic needs, they should know what their task are and supported by the equipment from the office. They also feel comfortable being a member of family at work place. From the chart above, most of the employee know what their task and the office provide enough equipment or tools to support their task. Since this is IT company, the computer is meet the software development requirement.

2) Work Driver

As the graph chart that shown in Figure 8, the work driver, employee enjoy the flexible hours of working. There is no strict time like office work hour 8 to 5 , they can start work as they like as long as the project is finished on time. Work task and work load is high, almost same as free time that they get. Free time here is their time to break for lunch, or while the project is done. But since the workload often high, they cannot enjoy their free time. This can be seen by the lowest point of this driver in work/life balance. The score for this element is just 3 point.

\section{3) Teamwork}

Teamwork consist of 6 elements as shown in Figure 9 above. There are small team, empowered, mutual respect, collaboration ,commit, and friends. The highest element in this driver is mutual respect, since every employee and superior respect each other as the family. There is no gap between them, and they are working together. The lowest point in this driver is small team, since many project that need to be handled, small team is not enough to handle every project. And this is correlate with high workload in Work Driver.

4) Growth Opportunity

The growth and talent focus of employee is measured from these elements, such as the employee recognition, performance, rewards, talent \& staffing, explore, dynamic, opportunities, career development, and progress. As the Figure 10 shown, the lowest point from this driver is 
The $1^{\text {st }}$ International Conference on Business and Engineering Management (IConBEM)

February $1^{\text {st }} 2020$, Institut Teknologi Sepuluh Nopember, Surabaya, Indonesia

recognition and rewards. With a poor reward and recognition can lead to 1 ack of motivated employee since reward and recognition provide important role on employee engagement and will cause the company suffer a poor performance (Sharon Suri Mesepy, 2016). The highest element in this driver is Dynamic. Employee is given space to keep learning from mistakes and encourage to do better. Given the chance to keep learning and learning from mistakes.

\section{5) Agility}

The agility is the ability to renew itself, adapt, change quickly, and succeed in a rapidly changing, ambiguous, turbulent environment in Figure 11. This consist customer focus, decision making, autonomy, diversity, and being themselves. Autonomy has the highest point and decision making is the lowest. But still for overall, the agility driver still managed on average. As for the autonomy, they can done their task with their way and not strictly managed as long as the task is finished. But, not all of them given a chance to make decision.

\section{F. Overall Result}

The most common finding from the feedback are related to their Motivation, Commit to do the best, sense of belonging, recognition, reward, and work life balance.

The positive results represent the total point for each driver that above $50 \%$. The top 3 are, commit $(91 \%)$, extert effort $(95 \%)$, and dynamic (91\%). Most of them is what makes drive the employee to strive more, to have more motivation in the flexible and dynamic work. They do want to give their best, and they enjoy their workplace.

This negative result is the total of subject driver that point below $50 \%$. The top 5 of the most lowest (under $30 \%$ ) is recognition $(23 \%)$, rewards $(23 \%)$, and worklife balance is the lowest (14\%). They feel like highest workload and low worklife balance, lack of recognition and rewards. They like the work environment but since the employee is at the age of productive, they dont want to stay longer in there

In addition, work/life balance is important for engagement and affects retention. As emphasized in a recent study on generations and gender by the Families and Work Institute, Generations $\mathrm{X}$ and $\mathrm{Y}$ have different workplace expectations than do the baby boomers and mature workers.

By using a matrix of engagement predictors (organizational process, values, management, role challenge, work/life balance, information, reward/recognition, work environment and products/services), HR can help the organization better manage engagement and ultimately foster motivation, productivity and retention.

\section{G. Solution Analysis}

PT Svara Inovasi Indonesia should focus on the top three of the lowest point to be improved and planned in order to increase the employee engagement which are rewards and recognition, and also work/life balance.

The priority is based on the total point that gained from questionnaire. The most important is work life balance since it was the lowest element of driver with total $14 \%$.

\section{1) Rewards and recognition}

Both of this element is the lowest among all. With 23\% point, this can represent that Svara is lack of recognition and reward. There is a direct and positive relationship between rewards and recognition and employee engagement. The direct translation of this could be that the better the rewards and recognition, the higher the levels of motivation and satisfaction, and possibly therefore, the greater the levels of performance and productivity that leads into more engaged employee.

For the rewards, Svara has to design the performance appraisal in order to know the right compensation for each of their employee. When it comes the reward, there must be lead to punishment. Svara should change the punishment into learning trough mistakes. Every mistakes can be learned and avoided in the future. The employee can be rewarded also if they do the mistakes. Encouraging them to be brave to fail in order to learn from mistakes.

Other alternatives is to give small rewards such as giving a prize for example a chocolates as a bonus that the employee never came late in a month. Or always be present in one month straight. This small kind of rewards can make employee feels more appreciated from the small things that they done, and also create company culture idirectly

For the recognition, Svara should create a culture that appraise every task that been done in front of the employee. Even not giving an amount of money, such as certificate the completion achievement. Small form of recognition also needed in order to create culture and grow the family bond that lead to employee engagement.

Other alternatives is to create employee of the month, by giving the certificate of completion or achievement in front of other employee. A small thanks can also include as recognition, to make employee feel more comfortable and recognize. The leader should be able to know the name of every employee, and call them by name. it's a small things but can be consider as recognition, that show the employee is existed in the company. Also, when there is a employee birthday, company can celebrate for just half hour before work hour done, by buying snacks or just celebrate.

\section{2) Work Life Balance}

Svara should offering benefits that reach beyond healthcare and into the employees personal concerns and responsibilities. Svara can offer workout classes in order to keep employee actives. Free lunch can be included in order to maintain the employee healthiness.

Since the high workload, Svara can offer 4 weeks of unpaid leave and 3-6 months of partially paid leave to be used for volunteerism or personal development. Svara can also held the annual vacation in order to release the stress.

Working remotely can also become other alternatives but need to build good connection and communication in order to keep collaborate with other team. Employee can also take half day work just to have some rest after a long period of projects.

Svara can also support employee interest such as hobbies to be developed. By giving the room or space to enhance their other skill and developed their hobbies, can also bring the balance to the work.

Since this is newly fresh start-up Svara need to develop company culture that lead to company performance, the early stage is the safest time period because the culture build along the growth of the company. In the time when the culture still 
The $1^{\text {st }}$ International Conference on Business and Engineering Management (IConBEM)

February $1^{\text {st }} 2020$, Institut Teknologi Sepuluh Nopember, Surabaya, Indonesia

developed, the team can trial and error of their culture and drivers, at this stage before forming solid culture.

The prioritize to improve based on the results are three drivers element, which are recognition and reward, and work life balance. Since the worklife balance is the lowest score from all elements, this has to be the most prioritized in order to increase the employee engagement.

\section{REFERENCES}

[1] G. O. Young, "Synthetic structure of industrial plastics," in Plastics, 2nd ed., vol. 3, J. Peters, Ed. New York: McGraw-Hill, 1964, pp. 15-64.
[2] W.-K. Chen, Linear Networks and Systems.Belmont,CA: Wadsworth, 1993, pp. 123-135.

[3] J. U. Duncombe, "Infrared navigation-Part I: An assessment of feasibility," IEEE Trans. Electron Devices, vol.ED-11, pp. 34-39, Jan. 1959.

[4] E. P. Wigner, "Theory of traveling-wave optical laser,"Phys. Rev., vol. 134, pp. A635-A646, Dec. 1965

[5] D. Ebehard and E. Voges, "Digital single sideband detection for interferometric sensors," presented at the 2nd Int.Conf. Optical Fiber Sensors, Stuttgart, Germany, 1984.

[6] G. Brandli and M. Dick, "Alternating current fed power supply," U.S Patent 4084 217, Nov. 4, 1978. 